\title{
Oxygen Therapy
}

National Cancer Institute

\section{Source}

National Cancer Institute. Oxygen Therapy. NCI Thesaurus. Code C94624.

The administration of oxygen to an individual, usually to aid in respiration. 